\title{
BMJ Open How do National Health Service (NHS) organisations respond to patient concerns? A qualitative interview study of the Patient Advice and Liaison Service (PALS)
}

\author{
Keegan Shepard, Ruta Buivydaite (D) , Charles Vincent (D)
}

To cite: Shepard K, Buivydaite R, Vincent C. How do National Health Service (NHS) organisations respond to patient concerns? A qualitative interview study of the Patient Advice and Liaison Service (PALS). BMJ Open 2021;11:e053239. doi:10.1136/ bmjopen-2021-053239

- Prepublication history and additional supplemental material for this paper are available online. To view these files, please visit the journal online (http://dx.doi.org/10.1136/ bmjopen-2021-053239)

Received 09 May 2021 Accepted 03 November 2021

D) Check for updates

(C) Author(s) (or their employer(s)) 2021. Re-use permitted under CC BY-NC. No commercial re-use. See rights and permissions. Published by BMJ.

Department of Experimental Psychology, University of Oxford, Oxford, UK

Correspondence to

Dr Ruta Buivydaite;

ruta.buivydaite@psy.ox.ac.uk

\section{ABSTRACT}

Objectives To describe the current work of the Patient Advice and Liaison Service (PALS) and assess the service's potential to resolve concerns and contribute to organisational learning.

Design A qualitative study using semistructured interviews.

Setting Four mental health trusts and four acute trusts in the English National Health Service, a total of eight PALS across different trusts.

Participants Twenty-four participants comprising of PALS staff and clinicians working with PALS teams.

Methods Semistructured interviews were undertaken with participants using video conferencing software. The framework method was used for the analysis of the large qualitative dataset, which is a conventional method of analysis, similar to thematic or qualitative content analysis.

Results PALS teams fulfil their core responsibilities by acting as point of contact for patients, providing information and resolving a variety of recurrent problems, including PALS staff communication, staff attitudes and waiting times. The remit and responsibilities of each PALS has often broadened over time. Barriers to resolving concerns included a lack of awareness of PALS, limited to no policies informing how staff resolve concerns, an emphasis on complaints and the attitude of clinical staff. Senior management had widely differing views on how the PALS should operate and the management of complaints is a much higher priority. Few PALS teams carried out any analysis of the data or shared data within their organisations.

Conclusions PALS teams fulfil their core responsibilities by acting as point of contact for patients, providing information and resolving concerns. PALS staff also act as navigators of services, mediators between families and staff and, occasionally, patient advocates in supporting them to raise concerns. PALS has the potential to reduce complaints, increase patient satisfaction and provide rapid organisational feedback. Achieving this potential will require more awareness and support within organisations together with updated national policy guidance.
Strengths and limitations of this study

- We were able to talk in depth to both Patient Advice and Liaison Service (PALS) teams, to gain a rich picture of the value work of they do and the challenges they face.

- The study sites were spread widely across England and involved acute, mental health organisations.

- This study was not able to assess how frequently PALS teams succeeded in resolving concerns or how their wider patient engagement and training of staff had been received.

- The clinicians interviewed were nurses, a midwife and two service managers as well as PALS team members; however, no physicians were interviewed in this study.

\section{INTRODUCTION}

While patients are generally very positive about the care they receive, many patients have concerns, whether or not they choose to raise these formally as complaints or claims. ${ }^{1-7}$ Serious adverse outcomes are more likely to lead to patients using the formal pathways to raise complaints or litigation; however, many other factors, such as whether patients receive apologies and explanations, are also critically important in determining how patients and families respond. ${ }^{8}$ Patient concerns, which go unaddressed, may lead to patients being reluctant to return to a healthcare organisation and less likely to follow the guidance of medical professionals. ${ }^{910}$

Patients, families and friends can raise concerns about their care with the Patient Advice and Liaison Service (PALS), which is provided in every National Health Service (NHS) trust in England (box 1). ${ }^{11}$ The service was first established in 2002 with the primary aim of supporting patients and families in raising concerns and this focus has remained 
Box 1 Description of Patient Advice and Liaison Service (PALS) and its responsibilities

\section{Key definitions}

- PALS-offers confidential advice, support and information on health-related matters. They provide a point of contact for patients, their families and their carers ${ }^{28}$ and aim to be noticeable and accessible within their National Health Service (NHS) trust.

- NHS trust-is an organisational unit within the NHS in England and Wales, generally serving either a geographical area or a specialised function. In any particular location, there may be several trusts involved in the different aspects of providing healthcare to the local population. $^{28}$

Key responsibilities

- Listen to the concerns, questions and comments raised by patients, carers, families and friends concerning their care or treatment.

- Provide helpful support, as well as accurate information and advice to resolve issues and concerns as quickly as possible.

- Assist NHS staff who are raising a concern on behalf of patients, which may involve liaising with other sites and healthcare organisations.

- Provide information and advice to individuals wishing to raise a formal complaint.

unchanged at the policy level. ${ }^{11}$ PALS maintains a presence within every NHS trust and provides services in person, by email, post and telephone. PALS teams have core duties established nationally (box 1) but are free to decide how to discharge these responsibilities. ${ }^{11}$ The approach of individual PALS teams depends on a variety of factors, including the population they serve, their level of funding and the approach taken by senior leadership in defining their local roles and responsibilities. ${ }^{12-14}$

Although the service existed for almost two decades, there are very few studies of its activities or effectiveness. This is surprising given the longstanding concern with the level of complaints and litigation and the potential of PALSs to resolve concerns at an early stage. Evans $e t$ $a l^{14}$ found that service users reported a high level of satisfaction with PALS even when their preferred outcome was not realised. They suggested that the service had the potential to reduce complaints and was extremely costeffective for the NHS. Since this report in 2008, the PALS has continued to operate with almost no external review or account of how the service has evolved in the two decades since its inception. ${ }^{14}$

This study aimed to describe the current work of PALS and to make a preliminary assessment of the potential of the service to resolve concerns and to facilitate learning from patient concerns. In particular, we aimed to explore: (1) the role of the PALS team, (2) the nature and response to concerns brought to PALS, (3) barriers and facilitators of concerns resolution and (4) how PALS data are used for wider learning within the host organisation.

\section{METHODS}

\section{Design}

The interviews were analysed using a well-established approach (framework method) described below. ${ }^{15}$ The data collection method of semistructured interviews was used with members of PALS teams and clinicians who worked with those teams.

\section{Participants}

We purposively selected eight NHS trusts, four mental health and four acute, spread widely across England. While we did not intend to make formal comparisons between acute and mental health PALS teams, we sought to capture the range of PALS activities in a diverse group of trusts. PALS teams were initially sent a description of the study and then contacted to discuss the study and invite them to participate. We asked to interview the PALS lead or manager and asked them to nominate a PALS officer and clinician familiar with their work. Participants were informed that the purpose of the study was to explore how organisations can best respond to patient concerns. All participants approached agreed to participate and none dropped out of the study.

We interviewed three people within each NHS trust, a PALS manager, PALS officer, or their equivalents, and a clinical member of staff suggested by the PALS manager, representing a total of 24 participants. All clinical participants had substantial experience of resolving patient concerns and experience of working with the PALS team. Five of the clinicians were nurses, one was a midwife and two were service managers. A sampling frame by NHS trust and role can be found in table 1 below.

\section{Development of semistructured interview}

The interview schedule development was informed by a literature review, three pilot interviews and discussion with patient advisors (online supplemental appendix I). The interview addressed a range of different topics, including the role of PALS teams, policies and guidance outlining their responsibilities, relationship between PALS and clinical staff, patient and staff awareness, barriers to resolving concerns, data collection and analysis as well as

Table 1 Sampling frame by NHS trust and role

\begin{tabular}{llll}
\hline & $\begin{array}{l}\text { PALS managers } \\
(\mathbf{N}=8)\end{array}$ & $\begin{array}{l}\text { PALS officers } \\
(\mathbf{N}=8)\end{array}$ & $\begin{array}{l}\text { Clinicians } \\
(\mathbf{N}=8)\end{array}$ \\
\hline Acute NHS trusts $(\mathrm{N}=4)$ & 4 & 4 & 4 \\
Mental health NHS trusts $(\mathrm{N}=4)$ & 4 & 4 & 4 \\
\hline
\end{tabular}

NHS, National Health Service; PALS, Patient Advice and Liaison Service. 
recommendations to improve going forward. Phrasing of specific questions varied slightly across the three types of participants but covered the same core content.

Participants were offered their preference of video conferencing software, including Microsoft Teams, Zoom and Skype, as well as an option to conduct the interview over the phone. In total, 24 semistructured interviews were conducted between July and October 2020, lasting an average of $41 \mathrm{~min}$ each. Data saturation was reached after interviewing the participants from the seventh trust; however, we continued interviewing as we aimed to have eight trusts in total (four mental health and four acute).

\section{Data analysis}

Interviews were audio recorded, transcribed verbatim and anonymised, before being uploaded onto 2018 QSR International's NVivo 12 software. The interviews were stored on password protected university computers. The seven stages of the framework method of data analysis were adhered to throughout the processes of analysis. ${ }^{16}$ Following familiarisation with the interviews, the process of coding was carried out with the first four transcripts to develop an initial analytical framework. Notes taken during and after interviews assisted in the identification of core themes. Any salient emergent categories were grouped into subdominant themes, which were subsequently grouped into broader dominant themes. The coding framework was reviewed and refined by the authors in successive iterations, before being reapplied to new transcripts, and further refined to produce the final coding framework (table 2).

The full data set was then tabulated in a matrix, which presented the data in a visually accessible and navigable format. A key feature of the framework method is the matrix output, which was pivotal in the identification of subdominant and dominant themes. Data analysis was carried out by one author (KS), with additional double coding of a sample of interviews by another author (RB) to ensure consistency of coding and interpretation. The two analysts had no prior connection with PALS, had never used the PALS and this was their first encounter with the service.

The initial results were shared with the participants and they provided the feedback, but the original themes did

\begin{tabular}{ll}
\hline Table 2 & Stages in the framework method of data analysis ${ }^{17}$ \\
\hline Stage & Procedure \\
\hline 1 & Transcribing interviews \\
2 & Familiarisation with transcripts \\
3 & Coding transcripts \\
4 & Developing analytical framework \\
5 & Applying analytical framework \\
6 & Tabulating data in matrix \\
7 & Interpreting data \\
\hline
\end{tabular}

not change. No major changes were made to the findings or further interviews undertaken.

\section{Participant anonymisation}

The participant's quotes were anonymised using the agreed coding method. Alphabetical letters were given to each participant and the numbers for their level of seniority were: 1 was PALS manager, 2 was PALS officer and 3 was the clinician. Each trust was given letter $\mathrm{T}$ and a number. Thus, (D1, T3) represents a PALS manager from trust 3 .

\section{Patient and public involvement (PPI)}

Two PPI lay research advisors from the Quality, Safety and Outcomes Policy Research Unit (www.qso.ac.uk) reviewed the design of study, the materials used, including the interview schedules, and provided comments on the findings.

\section{RESULTS}

A total of 24 participants, including eight PALS managers, eight PALS officers, or their equivalents, as well as eight healthcare staff working with PALS teams, were interviewed. Four dominant themes emerged from the analysis: the Role of PALS, Concerns and their Resolution, Barriers to Resolution and Learning from Concerns. Common themes were found across mental health and acute trusts, although the nature of concerns raised naturally varied in different contexts. For simplicity, we use the word 'patient' to broadly indicate the person raising the concern, while being aware that this may be a friend or family member, as well as that the term 'service user' is more commonly used in mental health organisations.

\section{The role of PALS}

PALS acts as a point of contact for patients and service users, to answer questions and respond to whatever concerns they have. PALS staff frequently contact clinicians to seek information and, where necessary, look for help in resolving conflicts or misunderstandings that have arisen. Additionally, PALS teams may be asked to provide information to those wishing to submit a formal complaint. Patients have the option to 'see them in person, on the telephone, email' (D1-T4), as well as through post and social media in most NHS trusts. There was no consensus from participants on which group, clinicians or PALS, was better suited for resolving concerns, as 'it depends on the concern' (E2-T5) and 'there are pros to both' (H3-T8).

PALS clearly continues to provide the services set out in the original policies and guidance. However, the PALS has evolved in different ways in each trust and their remit and responsibilities have often broadened considerably beyond their core duties. Almost all PALS managers and officers described the role of PALS as being a 'catch-all service' (E1-T5), where due to the operational pressures facing NHS trusts, they are used more as a switchboard 
to pick up calls and duties that no one else in their trust will do, as well as 'handle loads more than just patient concerns', as a result (E2-T5).

Their remit is to be that jam in the sandwich, if you like. So they are the portal. So when families or anybody make contact with a trust, that they are a way in, a route in, a funnel, if you like, for any concerns or questions or requests in any form. (B1-T2)

It's probably the case for most PALS teams. But we're...I think the easiest kind of metaphor is that we're kind of a sweeper in soccer terms with a sweeper, anything that no one else can deal with, people sort of direct it to us. (E1-T5)

Participants who described this catch-all service role said it resulted from a combination of the pressures on clinical staff, a lack of clear guidance and definition of their role within each trust as well as a lack of awareness of national policy on the part of senior staff in their respective trusts. However, despite the feeling that they fulfil duties and responsibilities beyond the scope of their role, they all emphasised that their central role is to be there for patients to provide help wherever and whenever they can.

I'm here for the patients, I'm happy to help anybody as much as I can. And, you know, and I hope I do a good job at the same time. (B2-T3)

\section{Resolution of concerns}

\section{What concerns do patients have?}

PALS staff reported that most patient concerns related to communication, staff attitudes and waiting times. Clinicians saw these same concerns frequently but emphasised that communication and clarity about discharge plans were the most frequent concerns.

A lot of them are about how long people have had to wait for appointments, that's one of the big concerns that comes through all the time. Another one is communication, actually, and how people hear things that doctors have said, or not hear them, that doctors have said to them or the way they've spoken to them, or you're not getting answers that they wanted to hear. (D1-T4)

Nine times out of ten, it's regarding discharge. It could be anything from discharges, having to wait for such a long time for their letters or their tablets to go home. (B3-T2)

A lot of it is just about communication and attitude and not getting answers when they want answers. (C3-T3)

Clinical staff and managers were clear that they saw resolving concerns as a legitimate part of their role, but that it required skills that not everyone has necessarily developed.
I think it's about using your skills that you might have developed as a clinician in terms of engagement, listening and so on and so forth. And just recognising that you've got that skill set, it's just turning it into a different function, you know, for a different outcome. (I3-T9)

\section{When does PALS become involved?}

Patients may come to PALS because they have not been able, for whatever reason, to resolve their concern or problem with clinical staff. However, patients may sometimes approach PALS directly, without first discussing their concern with clinical staff or managers as they may believe that raising their concern will have a negative impact on relationships with people caring for them or on their treatment. Clinicians who are aware of PALS may also contact the service directly or signpost the patient to PALS, if concerns cannot be resolved locally.

Once contacted, all PALS teams appeared to follow a structured process, where they liaised with the patient and clinician to find a solution to the problem presented.

A concern is received via email or by phone, and the PALS Officer will establish what the concern is. If it's very straightforward, they'll act upon it straightaway. If it's not straightforward, they'll need to contact the patient and then discuss what outcomes they're seeking. Once they understand, or believe that they understand, fully well what the outcome is that they're asking for, they'll take action. (C1-T3)

PALS staff are often able to find information for a patient simply because they know who to contact within their trust and how to contact them as a result of previously built relationships and experience. In this sense, they act as 'navigators' of the healthcare system and sometimes, more forcefully, as advocates for patients where a firmer approach is required.

The principal strengths of PALS were that they had more experience and 'a particular skill set' (F1-T6) for resolving concerns, as well as that they represent an impartial third party, acting as a mediator between clinicians and service users.

We're slightly removed, separate from that department. We are employed by the trust. But we're more like a third party that patients like so they don't feel like it's them versus the clinicians and NHS, you know, we're their back-up and mouthpiece. (A2-T1)

To do their job effectively, PALS staff do need time to build these relationships within the trust and to familiarise themselves with a particular ward, for instance, to better understand what happened and who was involved.

I think what becomes very tricky is if somebody external is investigating a complaint about the complex needs service and don't know how the service works. (F3-T6) 
Despite their different roles, all participants agreed that resolving concerns informally was preferable to resolving formal complaints, as the former requires fewer resources from the NHS trust and provides the service user with a much faster resolution.

The idea of PALS is that hopefully we can resolve things quicker so we can just walk up to a ward and see someone or we can go and chat to the ward sister or send a quick email or do a quick phone call. Whereas the complaints process is, you know, three days to acknowledge, 25 working days to respond. (A2-T1)

\section{Barriers to resolution of concerns}

Participants described several barriers that restrict the ability of both PALS and clinicians to resolve informal concerns within their trusts, including a lack of awareness of PALS, an absence of policies outlining the scope of their role, an emphasis on complaints instead of concerns by their organisations as well as an unavailability and attitude of clinical staff.

\section{Lack of awareness}

The most significant barrier was the perception in all eight trusts of a widespread lack of awareness of PALS and the services that they provide.

In my experience, clinical teams have a really bad understanding of what PALS is and what PALS does. (E2-T5)

They're only aware of them, really, if they've used them before or we inform them. There are posters up, you know, if you go to any ward at the moment, there's posters up about everything. And if you're sick in bed, you're not going to be reading those posters in reality. So, yes, it's up to us to inform them. (A3-T1)

In some cases, the location of PALS teams within NHS trusts contributed to lack of patient awareness. While the majority of PALS teams within acute NHS trusts had offices that were accessible to patients and located near a waiting area, PALS teams in mental health NHS trusts were largely inaccessible and hidden so that patients could only reach them by phone, letter or email, thereby reducing awareness.

I think from a patient or person coming to PALS, I don't think people are clear on what actually we do. So I think if you go into an acute service hospital, you're going to usually an office where it says PALS. (I1-T9)

\section{Lack of policies and guidance informing their application}

Almost all PALSs who participated in the study did not have clear policies or guidance within their trusts defining the scope of their role and responsibilities of the team. As a result, a majority of PALS staff questioned their individual role and wished for some written guidelines.
I'm not really sure what my role is properly at the moment. (I1-T9)

There needs to be some guidance for trusts to actually deliver what PALS really should be about. (A1-T1)

PALS managers noted that the lack of policies and guidance increased the variability of PALS teams across England and led to the misuse of PALS within some trusts.

It makes me quite sad when I hear about other trusts, when they are using PALS in a way that I just don't feel is appropriate. I don't feel it's the right way... and I'm certainly not saying we're perfect. Far from it. (A1-T1)

\section{Emphasis on complaints}

All participants reported that senior staff in every organisation paid much more attention to complaints than concerns, because complaints handling is a 'regulated service' (A1-T1) that is monitored by regulators. This led to a lack of understanding and appreciation of the role and value of PALS.

PALS does get overlooked and that happens within our trust. (E2-T5)

It felt very much like that PALS was a lower step down from complaints. (D2-T4)

Participants believed that this emphasis on complaints sometimes led to clinicians directing patients to submit a formal complaint, when PALS could have resolved the concern instead informally.

We have some consultants who feel that PALS is an unnecessary link in the chain and think "I'll address it and if I can't address it, then complaints will address it. (D2-T4)

\section{Attitude and unavailability of clinical staff}

Clinicians interviewed also reported that a majority of their clinical colleagues view PALS in a positive light but simply do not have time to liaise effectively. Additionally, PALS staff reported that they often cannot find specific clinicians due to a lack of updated contact details.

It's getting hold of the person who can solve the problem for us. You know, we can email a consultant, but he may not be able to get to his emails for a little while. (D1-T4)

Our services change every day, you know, people are moving in posts, you know, different managers, different services. Managers will move between services. Services will open and close. And no one will tell us. We have no way of knowing at all what services are open, what services are not, who's managing which service. (E2-T5)

\section{Learning from concerns}

While the principal remit of PALS is the resolution of individual concerns, there is clearly potential for reflecting 
on those concerns to inform wider learning and improvement. Incident reports and complaints are routinely reviewed to provide feedback and stimulate learning and improvement and participants argued that the same could be done for PALS data.

\section{What data are collected?}

In the collection of concerns data, it was clear that only a minority of PALS teams involved in the study had established a robust approach, which involved assigning specific categories to informal concerns, recording who was involved, relevant dates and the outcome; however, a large majority of PALS teams simply record a general description of the concern.

We have a whole host of codes that we use, including, for example, communication, lost property. So it's not what we think. So we don't think, 'well I don't think it was a staff member was rude', it is what the patient thinks. (C2-T3)

There aren't really any categories, so it's a complaint or a PALS inquiry or it's a local resolution. And then the detail of that complaint is just our account of it. So there's not a pull-down bar that says "it's this category, or that category, whatever. (I1-T9)

What is done with the data?

Few PALS teams or their organisations across England carried out no analysis of the data or reflected on the many patient concerns collected.

We're not analysing....all we're doing at the moment is counting the numbers. And the most detailed analysis that we do, which is all off of an Excel spreadsheet, is the number of days to completion. (I1-T9)

A recurring theme from the interviews was that there was no interest from senior trust staff in the patient concerns data and that all the emphasis is on formal complaints data.

The data that we produce has always been an addendum, really an appendix to the complaints material. (E1-T5)

At those meetings they talk about complaints, but they don't really ask what's going on, what the trends are. (I1-T9)

Participants acknowledged that there was no learning from informal concerns within their NHS trust and that the data were not shared beyond their organisation.

This may be shocking to you, as I wish I could say "Oh, yeah, PALS has done this and PALS has done that and we've affected loads of changes". As far as I'm concerned. No, we haven't. (E1-T5)

PALS data doesn't really get shared beyond the organisation, because there isn't that requirement. (C1-T3)

Despite not using concerns data to inform organisational learning, all participants understood the potential for PALS data to be used as an 'early warning system' (E1T5). For instance, participants described how patients tend to raise informal concerns immediately, whereas complaints may be raised months after an incident.

One of the things about PALS is that obviously it's pretty much real time feedback, whereas complaints is often delayed. People sometimes don't raise the complaint until a year after it's happened or six months or three months or whatever. (C1-T3)

\section{DISCUSSION}

PALS was established to provide support, information and advice to patients and families, as well as to resolve their concerns in a timely manner. PALS teams interviewed in this study are certainly fulfilling these core responsibilities. The PALS has however evolved in different ways in each trust and their remit and responsibilities have often broadened considerably beyond their core duties. Many of the teams have become a kind of 'catch-all' service taking on any patient liaison work not allocated elsewhere. Most participants reported that senior managers within their trusts seemed largely unaware of the core national responsibilities of PALS and, even within trusts, had widely differing views on how the PALS should operate. A recurring theme was that complaints were given much higher priority and that little interest was shown in the work of PALS. All staff agreed that interventions by PALS had the advantage of being much quicker, less burdensome to both patients and staff and more personal in nature than the formal complaints process.

PALS staff appear to adopt multiple different roles according to the needs of patients and families.

They certainly fulfil their core role of providing support, advice and information to patients. At times, however, PALS staff also appear to act as navigators of services, mediators between families and staff and, occasionally, patient advocates in supporting them to raise concerns. ${ }^{17-20}$ The role of navigator is particularly critical as patients often experience services as complex and not well integrated. ${ }^{21-23}$ We cannot of course, from this study, assess how often PALS staff adopt each of these roles or how often their intervention produces a successful outcome. However, they clearly do provide support to patients and families in a variety of ways, which appear not fully appreciated by their host organisations.

Most participants believed that PALS could achieve much more if the services were given more support and resources by senior management. Even within existing resources however, there is scope to develop the PALS by sharing examples of innovation across PALS teams. PALS could, for instance, be advertised much more widely in NHS organisations, in particular, by informing clinicians that PALS can support them as well as their patients. ${ }^{24}$ Some PALS staff are much more active than others and regularly visit wards to talk to patients, engage with staff and pre-empt potential problems. Some PALS teams were 
more proactive still in providing training to clinical staff on how to communicate effectively and resolve patient concerns at source.

There is currently no requirement for PALS teams to collect data or any guidance for them on how this might be done. Yet, concerns data represent a rich source of information, potentially timelier and more sensitive to patient experience than data from complaints. ${ }^{1}$ It would be relatively straightforward to produce a national framework for the recording and classification of patient concerns, which should have a strong emphasis on recording actions taken and outcomes. ${ }^{25} 26$ The existing framework for complaints could also be modified for less serious problems. ${ }^{27}$ This would allow organisations to learn from concerns and, equally important, allow wards and hospital services to monitor patient concerns near real time. ${ }^{14}$ This is particularly useful for detecting clusters of problems or a sudden escalation of problems in a particular area, which would be revealed much more quickly in PALS data than in complaints systems.

\section{Strengths and limitations}

This study is one of the very few to examine the role of PALS and the potential of services of this kind to resolve patient concerns and contribute to learning. To our knowledge, this is the only study of PALS in the last decade. We were able to talk in depth both to PALS teams and to clinicians and managers who worked with those teams to gain a rich picture of the work of PALS and the challenges they face. The study sites were spread widely across England and involved acute, mental health organisations. This qualitative study should however be considered only as an initial exploration of the work of PALS. In particular, we cannot be sure how frequently PALS teams succeed in resolving concerns or how their wider patient engagement and training of staff has been received.

\section{CONCLUSIONS}

PALS teams fulfil their core responsibilities by acting as a point of contact for patients, providing information and resolving a variety of recurrent problems. The remit and responsibilities of each PALS has often broadened considerably over time. Senior healthcare management had widely differing views on how the PALS should operate and viewed complaints as having a much higher priority. Few PALS teams carried out any analysis of collected data or shared data within their organisations. The role of PALS teams, with their focus on early resolution of concerns and potential problems, could be enhanced to potentially increase patient satisfaction and reduce the need for patients to make formal complaints.

Acknowledgements The authors would like to thank the eight participating NHS Trusts in England, as well as the PALS staff and clinicians who gave their time during the pandemic to contribute to this service evaluation. In addition, the authors would like to thank the two patient and public involvement lay research advisors, provided by the Quality, Safety and Outcomes Policy Research Unit, who enriched the quality of the service evaluation by contributing their unique and important perspectives. The authors thank Jules Forder, Ray Fitzpatrick and Helen Hogan for comments on an earlier draft of this manuscript.

Contributors KS and CV conceived the service evaluation and all authors contributed to its design. KS carried out all of the data collection. RB and KS carried analysis, while CV extensively supervised and provided support during the process. $\mathrm{KS}$ and RB drafted the manuscript and all of the authors reviewed and agreed on the current version.CV is acting as guarantor of this study

Funding This study was funded by the National Institute for Health Research (NIHR) Policy Research Programme, conducted through the Quality, Safety and Outcomes Policy Research Unit, PR-PRU-1217-20702. The views expressed are those of the author(s) and not necessarily those of the NIHR or the Department of Health and Social Care.

Competing interests None declared.

Patient consent for publication Not applicable.

Ethics approval This project has been reviewed by the Joint Research Office study classification group. It was determined that the activity described is best understood as a service evaluation. As such, it is not subject to the Department of Health's UK Policy Framework for Health and Social Care Research (2017). It requires neither sponsorship nor research ethics review. The study was assessed and categorised as a service evaluation by the local ethics committee. All participants provided written informed consent to take part in the interviews.

Provenance and peer review Not commissioned; externally peer reviewed.

Data availability statement Data sharing not applicable as no datasets generated and/or analysed for this study.

Supplemental material This content has been supplied by the author(s). It has not been vetted by BMJ Publishing Group Limited (BMJ) and may not have been peer-reviewed. Any opinions or recommendations discussed are solely those of the author(s) and are not endorsed by BMJ. BMJ disclaims all liability and responsibility arising from any reliance placed on the content. Where the content includes any translated material, BMJ does not warrant the accuracy and reliability of the translations (including but not limited to local regulations, clinical guidelines, terminology, drug names and drug dosages), and is not responsible for any error and/or omissions arising from translation and adaptation or otherwise.

Open access This is an open access article distributed in accordance with the Creative Commons Attribution Non Commercial (CC BY-NC 4.0) license, which permits others to distribute, remix, adapt, build upon this work non-commercially, and license their derivative works on different terms, provided the original work is properly cited, appropriate credit is given, any changes made indicated, and the use is non-commercial. See: http://creativecommons.org/licenses/by-nc/4.0/.

\section{ORCID iDs}

Ruta Buivydaite http://orcid.org/0000-0002-8258-2280

Charles Vincent http://orcid.org/0000-0003-0270-0222

\section{REFERENCES}

1 Anderson WG, Winters K, Auerbach AD. Patient concerns at hospital admission. Arch Intern Med 2011;171:1393-400.

2 Commission, C.Q. Survey finds most patients are positive about their hospital care, but many still experience delays when they leave, C.Q. Commission, editor, 2017.

3 Heyn L, Ruland CM, Finset A. Effects of an interactive tailored patient assessment tool on eliciting and responding to cancer patients' cues and concerns in clinical consultations with physicians and nurses. Patient Educ Couns 2012;86:158-65.

4 Mjaaland TA, Finset A, Jensen BF, et al. Patients' negative emotional cues and concerns in hospital consultations: a video-based observational study. Patient Educ Couns 2011;85:356-62.

5 Mulcahy L, Tritter JQ, Pathways P. Pathways, pyramids and Icebergs? mapping the links between Dissatisfaction and complaints. Sociol Health IIIn 1998;20:825-47.

6 O'Hara JK, Reynolds C, Moore S, et al. What can patients tell us about the quality and safety of hospital care? findings from a UK multicentre survey study. BMJ Qual Saf 2018;27:673-82.

7 Williams B. Patient satisfaction: a valid concept? Soc Sci Med 1994;38:509-16.

8 Vincent C, Young M, Phillips A. Why do people sue doctors? A study of patients and relatives taking legal action. Lancet 1994;343:1609-13. 
9 Burroughs TE, Waterman AD, Gallagher TH, et al. Patients' concerns about medical errors during hospitalization. Jt Comm J Qual Patient Saf 2007;33:5-14.

10 Burroughs TE, Waterman AD, Gallagher TH, et al. Patient concerns about medical errors in emergency departments. Acad Emerg Med 2005; $12: 57-64$.

11 Heaton J, Sloper P, Clarke S. Access to and use of NHS patient advice and liaison service (PalS): the views of children, young people, parents and PalS staff. Child Care Health Dev 2008;34:145-51.

12 Abbott S, Meyer J, Bentley J, et al. Patient advice and liaison services: strengthening the voices of individual service users in health-care organizations. Health Expect 2006;9:138-47.

13 Heaton J, Sloper P. National survey of patient advice and liaison services (PalS) in England: children, young people and parents' access to and use of PalS. Child Care Health Dev 2004;30:495-501.

14 Evans D, Booker S, Daykin N, et al. National evaluation of patient advice and liaison services (PalS), in final report. University of the West of England, 2008: 1-324.

15 Merriam SB, Merriam SB. Qualitative research : a guide to design and implementation. San Francisco: Jossey-Bass, 2009.

16 Gale NK, Heath G, Cameron E, et al. Using the framework method for the analysis of qualitative data in multi-disciplinary health research. BMC Med Res Methodol 2013;13:117.

17 Tho PC, Ang E. The effectiveness of patient navigation programs for adult cancer patients undergoing treatment: a systematic review. JB Database System Rev Implement Rep 2016;14:295-321.

18 Ellen ME, Shach R, Balicer RD. Helping patients help themselves: supporting the healthcare journey. Patient Educ Couns 2018;101:1708-11.
19 Kelly KJ, Doucet S, Luke A. Exploring the roles, functions, and background of patient navigators and case managers: a scoping review. Int J Nurs Stud 2019;98:27-47.

20 Gilbert JE, Green E, Lankshear S, et al. Nurses as patient navigators in cancer diagnosis: review, consultation and model design. Eur $J$ Cancer Care 2011;20:228-36.

21 Wennberg JE. Time to tackle unwarranted variations in practice. $B M$ 2011;342:d1513.

22 Neuhauser D, Provost L, Bergman B. The meaning of variation to healthcare managers, clinical and health-services researchers, and individual patients. BMJ Qual Saf 2011;20 Suppl 1:i36-40.

23 Mailloux C, Halesey E. Patient Navigators as essential members of the healthcare team: a review of the literature, 2018.

24 Montgomery CM, Chisholm A, Parkin S, et al. Wild data: how frontline hospital staff make sense of patients' experiences. Sociol Health IIIn 2020;42:1424-40.

25 Coulter A, Locock L, Ziebland S, et al. Collecting data on patient experience is not enough: they must be used to improve care. $B M J$ 2014;348:g2225.

26 Martin GP, McKee L, Dixon-Woods M. Beyond metrics? Utilizing 'soft intelligence' for healthcare quality and safety. Soc Sci Med 2015;142:19-26.

27 Reader TW, Gillespie A, Roberts J. Patient complaints in healthcare systems: a systematic review and coding taxonomy. BMJ Qual Saf 2014;23:678-89.

28 Services, N.H. What is PalS (patient advice and liaison service)? 2021. Available: https://www.nhs.uk/nhs-services/hospitals/whatis-pals-patient-advice-and-liaison-service/ [Accessed 28 Aug 2021] 